radicles for their carboxyl hydrogen, and benzoyl for the hydroxyl hydrogen, be converted into basic products which possess, in common with cocaine, the property of producing local anæsthesia. Eucaine belongs to this class of compounds and is the methyl ester of a methyl - benzoyl - triacetone - alkamine - carboxylic acid as shown by the formula ${ }^{2} \mathrm{NMe}<\mathrm{CMe}_{2} \cdot \mathrm{CH}_{2}>\mathrm{O}<\mathrm{COOMe}$ Recent observations indicating that eucaine hydrochloride has produced a burning sensation when applied to the eye have induced Silex to introduce a new compound of the same class which he finds to be better adapted for ophthalmic use. The name eucaine $\beta$ is proposed for this substance to distinguish it from the older eucaine, or eucaine $a$. Chemically it is closely allied to the latter and also to cocaine, and especially to tropacocaine, but it is less toxic than either of the two last-named substances. Though the hydrochloride of the new compound is less irritating it is in no way inferior in its anæsthetic action to that of eucaine $a$. The constitution of eucaine $\beta$ is represented by the formula : ${ }^{3}$

Liverpool.

$$
\mathrm{NH}<\underset{\mathrm{CHMe}}{\mathrm{CMe}_{2}} \cdot \underset{\mathrm{CH}_{2}}{\mathrm{CH}_{2}}>\mathrm{O}<\underset{\mathrm{OBz}}{\mathrm{H}}
$$

\section{A SEVERE CASE OF TRAUMATIC TETANUS SUCCESSFULLY TREATED WITH SERUM.}

By C. L. FRASER, F.R.C.P., F.R.C.S. EDIN.

A BOY, aged 12 years, received two cuts on the scalp by falling from a wall to the ground on April 14th, 1899. The wounds were well cleansed, stitched, and dressed, and they readily healed by first intention. On the 29th the patient complained of uneasiness in his neck, and the parents concluded that he had caught cold. On being examined there was found to be decided stiffness of the muscles of the back of the neck; the sterno-mastoids were also slightly tense, and the head was rigidly held in one position. On the 30th the stiffness of all the muscles was more pronounced, and on May 1st risus sardonicus appeared and the stiffness of the other muscles was still more pronounced. On the 2nd all the muscles of the back were found to be involved, so that the body was very rigid, and the head was much retracted. Swallowing, too, was sometimes very difficult. The head was still further retracted on the 3rd, and the muscles of the face were rigid. All the muscles of the neck, the back, the thorax, and the abdomen were as hard as boards, so that the patient could be rolled over like a log of wood. The pectorals and arms were so far free and there had been no violent spasm. Up to this point the patient had been taking large doses of chloral, but with very small appreciable results. On this date, too, it was observable that both legs were very stiff and rigid. Through the courtesy of the officials of the Jenner Institute a supply of anti-tetanic serum this day arrived and of this 10 cubic centimetres were injected at 12 noon, and at 10 P.M. 10 cubic centimetres more. On the 4th the pulse was 96 and the temperature was $99^{\circ} \mathrm{F}$. Spasms of the abdominal muscles were severe and painful. 10 cubic centimetres of the serum were injected. On the 5 th the patient, who had passed a very restless night owing to painful spasms of the abdominal muscles, had very marked risus sardonicus and swallowing was very difficult. There was no evident relaxation of any muscle. 10 cubic centimetres of the serum were injected. At 9 P.M. the patient was free from spasms and had slept peacefully for several hours. The pulse was 88 and the temperature was $98.4^{\circ} .10$ cubic centimetres of the serum were injected. On the 6th the patient had passed a restless night owing to an aperient having acted. The pulse was 96 and the temperature was $99 \cdot 2^{\circ}$. The muscles seemed to be slightly less tense and there were no spasms. 10 cubic centimetres of the serum were injected. On the 7th the patient had had a

2 Geng Merling: Berichte der Deutschen Pharmaceutischen Gesellschaft, Band vi. pp. 173-176. Journal of the Chemical Society, 1897, September A 1, 499. Translation in the Pharmaceutical Journal, Oct. 17th, 1896, p. 337 .

Year Book of Pharmacy, 1897, p. 244, from Pharmaceutisches Dentralblatt, Band xxxviii., p. 355 . good night, having slept soundly, and he was perfectly free from spasm. The muscles were less tense and he could elevate the knees a little. The pulse was 96 and the temperature was $99^{\circ}$. 10 cubic centimetres of the serum were injected. On the 8th the patient had had another excellent night, having slept well and having been free from spasm. The muscles of the head and the neck were considerably relaxed so that the head was quite moveable. He could nod and pull up the knees. 10 cubic centimetres of the serum were injected. On the 9th the muscles were still more relaxed. The movements of the previous day could be better executed and the muscles of the abdomen seemed to be not quite so hard. The patient lay perfectly quiet, complaining only of a slight stinging sensation in the wounds but there was nothing unusual to be seen. On the 10th there was a much freer movement of all the affected muscles and the patient could move his head freely from side to side and raise both knees. The abdominal muscles were much relaxed.

The subsequent history of the case is one of regular and almost uninterrupted improvement. On the 13th an irritable roseolous eruption appeared on the chest and abdomen which was ascribed to the use of the serum, but it speedily disappeared. On the 15 th a small periosteal abscess formed below one of the scars on the scalp. This was incised and the pus was at once forwarded to the Jenner Institute. The officials there very kindly made cultures from it and injected guinea-pigs but with a negative result. The case seems to be worthy of notice from the fact that it was a severe one and the reaction to the use of serum highly probable.

Berwick-on-Tweed.

\section{CASES OF AMENORRHEA ASSOCTATED WITH RAYNAUD'S DISEASE AND PULMONARY TUBERCULOSIS. ${ }^{1}$}

\section{BY JOHN W. BYERS, M.A., M D., M.A.O. (HON. CAUSÂ), R.U.I,}

PROFESSOR OF MIDTIFERY, QUEEN'S COLLEGE, BELFAST,

DURING the past ten years I have met with a series of cases which present certain well-defined clinical features. These prominent characteristics are: (1) diminished or arrested menstruation; (2) local symmetrical asphyxia of the extremities, especially the arms and hands-a condition known as "Raynaud's phenomena"; and (3) pulmonary tuberculosis. The presence of any single one of these symptoms in patients is observed every day, but I do not think that attention has hitherto been called to the remarkable association of all of these clinical features in the same individual. This trilogy of symptoms did not always appear contemporaneously in each of the patients who were affected. In all of them when first seen by me the local asphyxia and the irregularity of menstruation were marked; in two of the patients pulmonary tuberculosis was also co-existent with the other clinical features which I have mentioned, while in two other patients it developed at a subsequent period. I shall now give details of four cases.

CASE 1.-I was consulted in 1892 in reference to a young woman in her seventeenth year with a history that she had been first "unwell" at 15 years of age when residing abroad. During the year preceding that in which I saw her, while she was living at the seaside, the periods had become gradually less and they had completely ceased for the previous three months. While living at the seacoast, at rather an unsheltered place, she noticed that if she was exposed to cold - and she thought bathing first brought on an attack-her hands and arms, for almost half the distance to the elbows, became cold and " went blue." She felt no other sensations in the affected parts. The same signs appeared in the feet but to a less degree. She was thin, but on examination no signs of any organic disease conld be detected. The hands and arms, from a point half-way between the elbows and wrists to the tips of the fingers, were cold to the touch, and in appearance presented a markedly bluish aspect, very much like the hue of a child who is the subject of " blue asphyzia." The radial arteries were dis tinctly felt and there was no tenderness along any of

1 A paper read before the British Mtdical Association, August 3rd, 1899. 